\title{
SEGURANÇA DO TRABALHO EM UNIDADES DE BENEFICIAMENTO DE PRODUTOS AGRÍCOLAS
}

\author{
WORK SAFETY IN AGRICULTURAL PACKING HOUSES
}

ROBERTO F. ABRAHÃO'

MAURO J.A.TERESO²

MARCO A. MARTINS ${ }^{3}$

\section{RESUMO}

Esta pesquisa teve como objetivo principal a identificação dos fatores de risco de acidentes laborais em unidades de beneficiamento de produtos agrícolas (UB). A pesquisa foi realizada em seis UB representativas da região de Campinas, empregando-se entrevistas abertas e semi-estruturadas, registros por meio de filmagens e fotos, observações diretas e sistemáticas de tarefas e medições de variáveis ambientais. Os riscos observados foram classificados em físicos, químicos, biológicos, ergonômicos e de acidentes. Para cada risco identificado foram discutidas possíveis conseqüências e sugestões. Como produto deste trabalho, foi construída uma lista de verificação (checklist) detalhada, com várias questões objetivas, relativas aos aspectos de segurança do trabalho em unidades de beneficiamento de produtos agrícolas.

Palavras-chaves: Segurança laboral, Unidades de beneficiamento, Fatores de risco.

\footnotetext{
${ }^{1}$ professor livre - docente, FEAGRI / UNICAMP, Campinas, SP. E-mail: roberto@feagri.unicamp.br.

${ }^{2}$ professor livre - docente, FEAGRI / UNICAMP.

${ }^{3}$ mestre em Engenharia Agrícola, FEAGRI / UNICAMP.
} 


\section{ABSTRACT}

This research's main objective was the identification of the risk factors of labour (work-related) accidents in packing houses. Open and semi-structured interviews, photografic and filmed registers, direct observations and systematic observations of tasks had been carried through in six Campinas region's UB. The EWA application allowed the understanding of the workers' difficulties, relative to aspects of workplace safety, analysed on the grounds of Labour Laws (NR) and Brazilian Standard 5413 (NBR). The risks were classified in Physical, Chemical, Biological, Ergonomic and of Accident. For each identified risk, were presented the possible consequences and suggestions. As a product of this work, it was built a detailed checklist, containing many objective questions, relative to the aspects of workplace safety in tomato processing unities.

Keywords: Work safety, Packing house, Risk factors.

\section{INTRODUÇÃO}

Em razão das crescentes exigências de qualidade e competitividade, as unidades de beneficiamento de produtos agrícolas (UB) ganharam importância no agronegócio brasileiro. Destaca-se a preocupação com os aspectos de segurança do trabalho nestes ambientes. Entretanto, são escassas as pesquisas realizadas em UB que focam questões ergonômicas e de segurança laboral (SIMCOX et al., 2001; KADER, 2002) e a maior parte delas têm como foco a produtividade do trabalho, além de aspectos ligados à tecnologia dos equipamentos.

Após a colheita, os produtos agrícolas precisam ser limpos, selecionados, classificados e acondicionados para posteriormente serem armazenados e distribuídos. A Figura 1 mostra 0 fluxo de produção em uma UB de tomate de mesa (RIBEIRO, 2007).

As tarefas predominantes confiadas aos operadores em uma UB são a movimentação manual de cargas (MMC) e a inspeção/seleção dos produtos. O processo de beneficiamento tem início com a chegada do caminhão carregado com caixas de tomates. Segue-se a descarga e o armazenamento das caixas no galpão. A próxima etapa, chamada de alimentação, consiste na virada ou tombamento das caixas de tomate na entrada da esteira. 


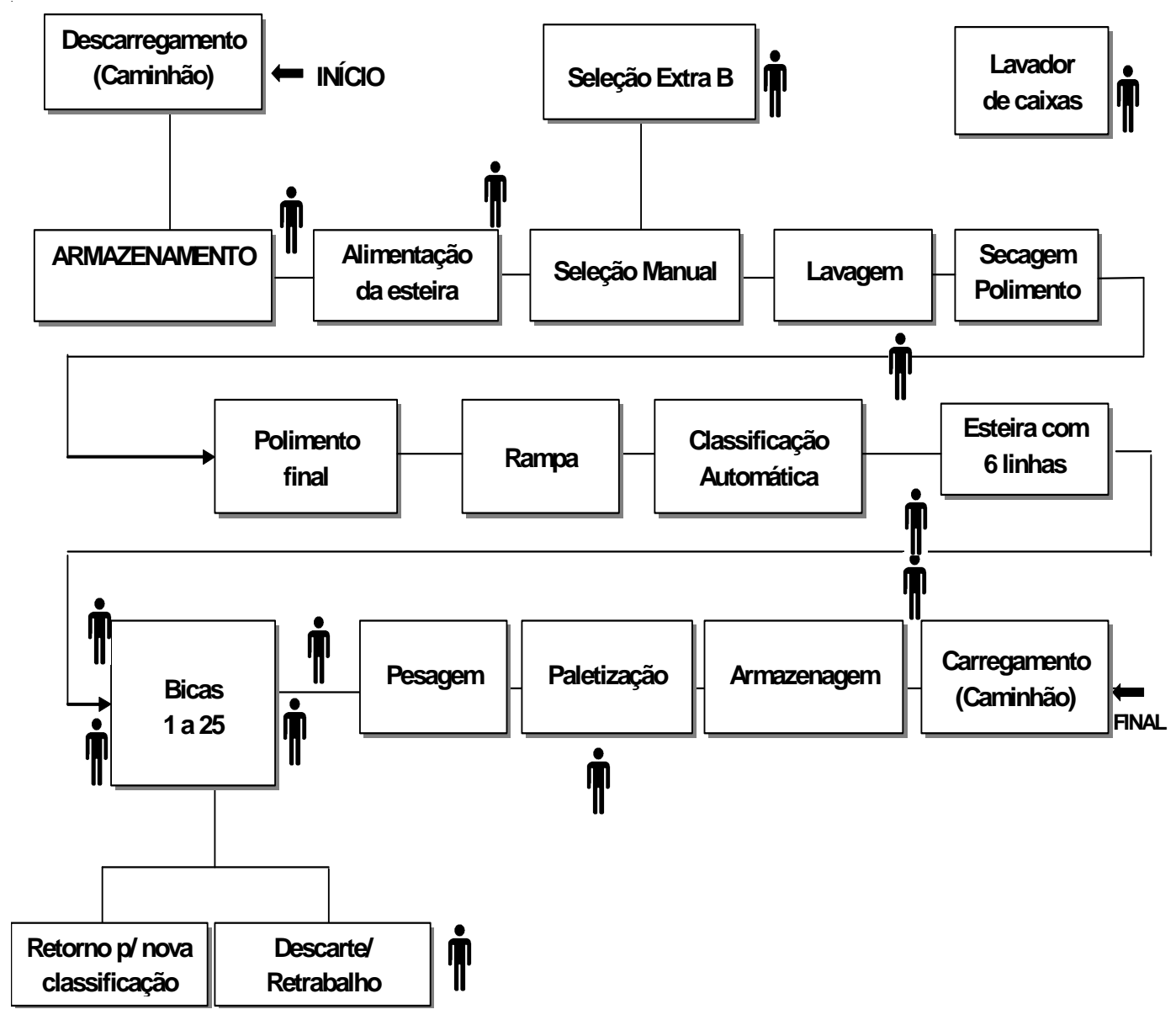

FIGURA 1 - Fluxo da produção em uma Unidade de Beneficiamento de tomates

\section{MATERIAL E MÉTODOS}

No posto de seleção os tomates são selecionados manualmente, retirando-se os defeituosos ou fora do padrão. Os tomates descartados são lançados em uma canaleta e seguem por gravitação para caixas plásticas. Segue-se a lavagem - por meio de gotejadores, utilizando-se o mínimo possível de água para evitar a contaminação dos frutos - e a secagem e polimento dos tomates. Depois, é feita a classificação automática por tamanho e cor. Os tomates seguem para o posto de seleção de bicas, onde os frutos são depositados em caixas plásticas, de madeira ou de papelão. As caixas são pesadas e paletizadas. Ao final do processo executa-se a limpeza dos equipamentos e do galpão.

Esta pesquisa procurou identificar os fatores de risco em UB de produtos agrícolas e construir uma lista de verificação (checklist) referente à inspeção de segurança do trabalho nestes ambientes laborais.
Adotou-se a tipologia empregada por GONÇALVES (1996); NERY et al., (1996) e ARAÚJO (2003), que classifica os fatores de risco de acordo com sua natureza, em riscos físicos, químicos, biológicos, ergonômicos e de acidentes.

Para a realização dessa pesquisa foram selecionadas por amostragem intencional um total de seis unidades de beneficiamento de tomate, descritas como UB1 (onde se realizou um estudo piloto), UB2, UB3, UB4, UB5 e UB6, todas no estado de São Paulo. A amostra procurou contemplar diferentes volumes de produção e níveis tecnológicos. Com a finalidade de proporcionar uma melhor compreensão do funcionamento geral das unidades de beneficiamento foi aplicado parcialmente o método da Análise Ergonômica do trabalho (GUERIN et al, 2001). Este procedimento possibilitou 0 conhecimento das tarefas e atividades

BioEng, Campinas, v.3 n.3, p.209-219, Set/Dez., 2009 
desenvolvidas em cada UB e um primeiro contato com os fatores de risco laboral.

Foram realizadas entrevistas, observações diretas, registros por meios de anotações, fotografias e filmagens para compreender como os operadores realizavam seus trabalhos e os riscos aos quais estavam expostos.

Procurou-se levantar dados sobre condições de segurança à luz da legislação vigente: NR-7, que normatiza a construção do Plano de Prevenção de Riscos Ambientais (P.P.R.A.); NR9, que normatiza a construção do Plano de Controle Médico e de Saúde Ocupacional (P.C.M.S.O.); NR15 , que regula a exposição aos fatores ambientais; NR-17, norma de ergonomia; e NBR-5413, que regula iluminância de interiores.

A elaboração da lista de verificação referente à inspeção de segurança do trabalho envolveu a observação de fatores relativos à edificação, pisos, escadas fixas, rampas, instalações elétricas, organização e limpeza geral, ruído, iluminação, temperatura, uso de equipamentos de proteção individual, condições de segurança das máquinas que beneficiam os tomates, das caixas de tomate, empilhadeiras, paleteiras, equipamento de combate a incêndio, sinalização de segurança, condições de segurança nos escritórios e riscos ergonômicos.

Para avaliação dos níveis de ruído nos diferentes postos nas UB utilizou-se um dosímetro digital marca Dupont, modelo MK3, calibrado, com o equipamento fixado na cintura do trabalhador $\mathrm{e}$ o microfone eletrolítico preso próximo à região auditiva (lapela), conforme anexo № 1 da NR-15.

$\mathrm{Na}$ avaliação da iluminância foi utilizado luxímetro analógico de marca Gossen, modelo Panlux eletronic 2. Os resultados obtidos procuraram sempre refletir as situações mais desfavoráveis aos trabalhadores. Os níveis mínimos foram obtidos da Norma NB-57 da ABNT, registrada como NBR 5413 no INMETRO, que se refere a valores de iluminância para interiores.
$\mathrm{Na}$ avaliação da temperatura (sobrecarga térmica) foi utilizado termômetro digital, modelo RSS 214 (bulbo úmido natural, bulbo seco e termômetro de globo), colocado nos postos de trabalho na altura do tórax dos trabalhadores. Foi calculado o IBUTG ${ }^{1}$ médio ponderado e comparado com o metabolismo exigido pela atividade em Kcal/ h do quadro № 3 da NR -15 e os limites de tolerância do quadro № 2 da NR-15.

Todos os dados foram efetuados em condições reais de trabalho, de modo que as medições e as observações não interferissem na rotina dos funcionários.

\section{RESULTADOS E DISCUSSÃO}

A Tabela 1 apresenta as características das diferentes UB, ressaltando o número de operadores envolvidos na movimentação manual de cargas e nas tarefas de seleção, os volumes de produção da UB, o número de linhas de classificação, os valores de iluminância, e o layout dos galpões e das linhas de beneficiamento.

O levantamento dos níveis de ruído na UB1 (estudo piloto) revelou que em todos os seus postos os valores estavam abaixo do limite de tolerância, que é de $85 \mathrm{~dB}(\mathrm{~A})$, conforme anexo $\mathrm{n}^{\circ}$ 1 da NR 15. Posteriormente, o mesmo levantamento nas demais UB também revelou que os níveis de ruído em todos os postos apresentaram-se dentro dos limites de tolerância.

Nos postos de seleção e no de bicas da UB1, a iluminância medida apresentou-se bem abaixo do recomendado pela literatura, que é de no mínimo 1000 lux (MILLER, 1992).

Posteriormente, as mensurações de iluminância nestes mesmos postos nas outras cinco UB também revelaram valores muito abaixo dos 1000 lux recomendados. 
TABELA 1 - Características das Unidades de Beneficiamento

\begin{tabular}{|c|c|c|c|c|c|c|}
\hline Parâmetro/característica & UB1 & UB2 & UB3 & UB4 & UB5 & UB6 \\
\hline № de operadores na seleção & 10 & 13 & 17 & 07 & 14 & 12 \\
\hline Produção caixas/mês & 8.000 & 163.800 & 458.640 & 4.800 & 131.040 & 112.320 \\
\hline № de operadores em MMC & 09 & 11 & 12 & 09 & 08 & 14 \\
\hline $\begin{array}{c}\text { Número de linhas de } \\
\text { classificação }\end{array}$ & 03 & 06 & 02 & 03 & 04 & 02 \\
\hline Iluminância- Bicas (lux) & 250 & 160 & 880 & 790 & 800 & 210 \\
\hline Iluminância- Seleção (lux) & 240 & 480 & 813 & 520 & 615 & 450 \\
\hline Iluminância -Alimentação (lux) & 230 & 190 & 521 & 430 & 600 & 290 \\
\hline Galpão & Adaptado & Adaptado & Projetado & Adaptado & $\begin{array}{c}\text { Parcialmente } \\
\text { Projetado }\end{array}$ & $\begin{array}{c}\text { Parcialmente } \\
\text { Projetado }\end{array}$ \\
\hline $\begin{array}{c}\text { Layout da linha de } \\
\text { beneficiamento }\end{array}$ & linha reta & linha reta & linha reta & em L & em E & linha reta \\
\hline
\end{tabular}

A partir das verbalizações, das descrições das atividades e das observações efetuadas, foram identificados os seguintes problemas de segurança na UB1: caixas de madeira com farpas e grampos expostos; hélices dos secadores sem as proteções; piso escorregadio nos postos de carregamento, descarregamento e seleção; extintores de incêndio obstruídos; ausência de guarda-corpo nas plataformas; não utilização de equipamentos de proteção individual em todos os postos; improvisação de plataforma elevadora feita com caixa de madeira no posto de seleção, piso sem demarcação.

A Tabela 2 constitui uma síntese dos fatores de risco observados em pelo menos uma das seis UB visitadas. Como é possível verificar, existem riscos de todas as naturezas e em todos os postos.
A maioria das UB não fornecia os equipamentos de proteção individual - luvas de raspa, calçado de segurança com biqueira de aço, óculos de proteção - adequados às tarefas empreendidas pelos operadores. Entretanto, mesmo nas UB que forneciam estes equipamentos, os trabalhadores não os utilizavam.

Metade das UB estudadas não possuía o P.C.M.S.O. (Programa de Controle Médico de Saúde Ocupacional) e o P.P.R.A. (Programa de Prevenção de Riscos Ambientais), programas obrigatórios descritos pelas normas NR-7 e NR-9.

O conjunto de dados e informações coletadas serviu de base para a construção da lista de verificação de segurança (check list) para unidades de beneficiamento, principal produto deste trabalho, apresentada no final deste artigo. 
TABELA 2 - Riscos laborais observados nas UB

\begin{tabular}{|c|c|c|c|c|c|}
\hline POSTOS & RISCOS & RISCOS & RISCOS & RISCOS & RISCOS DE ACIDENTES \\
\hline $\begin{array}{l}\text { Descarrega- } \\
\text { mento }\end{array}$ & & & & $\begin{array}{l}\text { intensa } \\
\text { movimentação } \\
\text { manual de } \\
\text { cargas } \\
\text { esforço físico } \\
\text { intenso }\end{array}$ & $\begin{array}{l}\text { piso escorregadio } \\
\text { ausência de sinalização de } \\
\text { segurança } \\
\text { falta de proteção nas } \\
\text { plataformas }\end{array}$ \\
\hline Alimentação & $\begin{array}{l}\text { sobrecarga } \\
\text { térmica }\end{array}$ & & & $\begin{array}{l}\text { intensa } \\
\text { movimentação } \\
\text { manual de } \\
\text { cargas }\end{array}$ & $\begin{array}{l}\text { ausência de sinalização de } \\
\text { segurança }\end{array}$ \\
\hline Seleção & $\begin{array}{l}\text { sobrecarga } \\
\text { térmica }\end{array}$ & $\begin{array}{l}\text { contato da } \\
\text { pele com } \\
\text { agro- } \\
\text { tóxicos }\end{array}$ & $\begin{array}{l}\text { contato da } \\
\text { pele com } \\
\text { fungos e } \\
\text { bactérias }\end{array}$ & & $\begin{array}{l}\text { - ausência de barreiras de } \\
\text { proteção em partes móveis } \\
\text { - risco de captura dos dedos } \\
\text { devido a distância dos } \\
\text { roletes } \\
\text { - piso escorregadio } \\
\text { - plataformas elevatórias } \\
\text { improvisadas }\end{array}$ \\
\hline $\begin{array}{l}\text { Bicas de Saída } \\
\text { e Embalagem }\end{array}$ & $\begin{array}{l}\text { sobrecarga } \\
\text { térmica } \\
\text { - ruídos }\end{array}$ & & & $\begin{array}{l}\text { intensa } \\
\text { movimentação } \\
\text { manual de } \\
\text { cargas }\end{array}$ & $\begin{array}{l}\text { ausência de barreiras de } \\
\text { proteção em partes móveis } \\
\text { ausência de sinalização de } \\
\text { segurança }\end{array}$ \\
\hline Pesagem & $\begin{array}{l}\text { sobrecarga } \\
\text { térmica }\end{array}$ & & & $\begin{array}{l}\text { intensa } \\
\text { movimentação } \\
\text { manual de } \\
\text { cargas }\end{array}$ & $\begin{array}{l}\text { caixas com farpas e } \\
\text { grampos expostos } \\
\text { ausência de sinalização de } \\
\text { segurança }\end{array}$ \\
\hline $\begin{array}{l}\text { Paletização e } \\
\text { Armazena- } \\
\text { mento }\end{array}$ & $\begin{array}{c}\text { - sobrecarga } \\
\text { térmica }\end{array}$ & & & $\begin{array}{l}\text { intensa } \\
\text { movimentação } \\
\text { manual de } \\
\text { cargas }\end{array}$ & $\begin{array}{l}\text { ausência de sinalização de } \\
\text { segurança } \\
\text { estrados de madeira em } \\
\text { más condições }\end{array}$ \\
\hline Carregamento & & & & $\begin{array}{l}\text { intensa } \\
\text { movimentação } \\
\text { manual de } \\
\text { cargas } \\
\text { esforço físico } \\
\text { intenso }\end{array}$ & $\begin{array}{l}\text { - piso escorregadio } \\
\text { - ausência de sinalização de } \\
\text { segurança } \\
\text { - falta de proteção nas } \\
\text { plataformas }\end{array}$ \\
\hline $\begin{array}{l}\text { Todos os } \\
\text { Postos }\end{array}$ & & & & $\begin{array}{l}\text { trabalho } \\
\text { noturno }\end{array}$ & $\begin{array}{l}\text { - caixas com farpas e } \\
\text { grampos expostos } \\
\text { - iluminância inadequada } \\
\text { - ausência de sinalização de } \\
\text { segurança } \\
\text { - extintores de incêndio } \\
\text { obstruídos } \\
\text { - falta de organização e } \\
\text { limpeza } \\
\text { - não uso de EPI } \\
\text { - painéis elétricos sem } \\
\text { proteção }\end{array}$ \\
\hline
\end{tabular}




\section{CONCLUSÕES}

As jornadas de trabalho prolongadas e 0 trabalho noturno são comuns à maioria das UB. Sob estas circunstâncias, as tarefas de movimentação manual de cargas e de seleção precisam ser planejadas levando-se em conta a necessidade de períodos de repouso para que os riscos de acidentes e de erros sejam minimizados devido à fadiga dos operadores.

Os principais riscos de acidentes identificados nas UB estão relacionados à manipulação de caixas de madeira com farpas, pregos e grampos expostos. Além disso, destacase a ausência de barreiras mecânicas nos elementos de máquinas dos equipamentos \% eixos, engrenagens, correntes, ventiladores. A maioria das UB também não conta com sinalizações de segurança que alertem os operadores para situações de risco.

Nas UB, os principais fatores de risco ergonômicos estão associados às tarefas de movimentação manual de cargas e de inspeção, devido ao intenso esforço físico, à repetitividade e às posturas corporais inadequadas.

Os riscos químicos e biológicos estão relacionados ao contato das mãos dos operadores, desprovidas de luvas, com o produto na seleção \% os tomates chegam do campo com resíduo de agrotóxicos e aqueles descartados podem conter patógenos biológicos. A lista de verificação desenvolvida neste trabalho pode ser utilizada com pequenas adaptações em UB que processem outros produtos agrícolas.

\section{REFERÊNCIAS BIBLIOGRÁFICAS}

ARAÚJO, A. K. Avaliação dos riscos ambientais da divisão de produtos do laboratório central de saúde pública do Ceará. Laboratório Central de Saúde Pública (LACEN - CE) 2003. 56p. (Especialização em Alimentos e Saúde Pública) Faculdade de Farmácia, Odontologia e Enfermagem, Universidade Federal do Ceará.

BRASIL. Agência Brasil. Empresa Brasil de Comunicação. Brasil gasta $R \$ 32$ bilhões anuais com acidentes do trabalho. Disponível em : <http://www.agenciabrasil.gov.br/noticias/ 2007/07/27/materia.2007-07-27.2077542540/ view>. Acesso em 16 out. 2007.
BRASIL. Ministério da Previdência e Assistência Social. Acidentes do trabalho por atividades econômicas, 2005. Disponível em: <http://www. Previdencia.gov.br/aeps2005/docs/5c30_04.xls>. Acesso em 20 nov. 2006.

DATAPREV. Índices de acidentes do trabalho dos últimos 25 anos. Revista CIPA, São Paulo, v.27, n. 323, p.84, 2006.

GONÇALVES, E. A. Segurança e Medicina do Trabalho: em 1.200 perguntas e respostas. São Paulo: L.Tr., 1996. 648p.

GUERIN, F.; LAVILLE, A.; DANIELLOU, F.; DURAFFOURG, J.; KERGUELEN, A. Compreender o trabalho para transformá-lo: a prática da ergonomia. São Paulo: Edgard Blucher, 2001.

KADER, A.A.. Postharvest technology of horticultural crops. 3.ed. Los Angeles: University of California, 2002. 535p.

MILLER, B. Lighting for grading. University of Florida, USA, Packinghouse Newsletter, Mount Vernon, NY, n. 166 p. 1-4, feb. 1992.

NERY, D. M.; ALBERTO, E.; BLASCO, J. C.; SILVA, J. H.; PINEDA, M. I. M.; CARVALHO, M. R.; SOARES, S. V.; ALBUQUERQUE, V. G. C. Comissão interna de prevenção de acidentes. 28. ed. São Paulo: SENAI, 1996.

SIMCOX, N.; FLANAGAN, M.; CAMP, J.;SPIELHOLZ, P.; SYNDER, K. Musculoskeletal risks in Washington State Apple Packing Companies. Seattle: Field Research \& Consultation Group, University of Washington, Department of Environmental Health, 2001. 103p.

RIBEIRO, I.A.V. Análise ergonômica do trabalho em unidades de beneficiamento de tomate de mesa: movimentação manual de cargas. 183p. Dissertação (mestrado em Engenharia Agrícola) Faculdade de Engenharia Agrícola, Universidade Estadual de Campinas, Campinas, 2007. 


\begin{tabular}{|c|c|c|c|c|}
\hline $\begin{array}{c}\text { LISTA DE VERIFICAÇÃO } \\
\text { INSPEÇÃO DE SEGURANÇA DO TRABALHO EM UNIDADES DE } \\
\text { BENEFICIAMENTO DE TOMATE }\end{array}$ & \multicolumn{4}{|c|}{$\begin{array}{l}\text { Folha: } \\
1 / 5\end{array}$} \\
\hline \multicolumn{5}{|l|}{ Local : } \\
\hline \multicolumn{5}{|l|}{ Data : } \\
\hline \multicolumn{5}{|l|}{ Responsável: } \\
\hline ASSUNTOS & $\mathbf{s}$ & $\mathbf{N}$ & $\mathbf{P}$ & NA \\
\hline \multicolumn{5}{|l|}{ EDIFICAÇÃO } \\
\hline \multicolumn{5}{|l|}{ 1. Estado geral em boas condições? } \\
\hline \multicolumn{5}{|l|}{ 2. Telhado em boas condições? } \\
\hline \multirow{2}{*}{\multicolumn{5}{|c|}{$\begin{array}{l}\text { 3. Portas e janelas em boas condições? } \\
\text { PISOS }\end{array}$}} \\
\hline & & & & \\
\hline \multicolumn{5}{|l|}{ 1. Sem risco de escorregamento? } \\
\hline \multicolumn{5}{|l|}{$\begin{array}{l}\text { 2. Sem saliências ou depressões que prejudiquem a circulação de } \\
\text { pessoas ou a movimentação de materiais? }\end{array}$} \\
\hline \multicolumn{5}{|l|}{ 3. Suporta as cargas móveis e fixas para as quais a edificação se } \\
\hline \multicolumn{5}{|l|}{ 4. Limpos? } \\
\hline \multicolumn{5}{|l|}{ 5. Desobstruídos? } \\
\hline \multirow{2}{*}{\multicolumn{5}{|c|}{$\begin{array}{l}\text { 6. Demarcados? } \\
\text { ESCADAS FIXAS }\end{array}$}} \\
\hline & & & & \\
\hline \multicolumn{5}{|l|}{ 1. Dotadas de corrimão e rodapé (NR18)? } \\
\hline \multicolumn{5}{|l|}{ 2. Sem risco de escorregamento (NR8)? } \\
\hline \multicolumn{5}{|l|}{$\begin{array}{l}\text { 3. Oferecem resistência suficiente para suportar as cargas móveis e } \\
\text { fixas para as quais a edificação se destina (NR8)? }\end{array}$} \\
\hline \multicolumn{5}{|l|}{ 4. Corrimão e rodapé em bom estado de conservação? } \\
\hline \multicolumn{5}{|l|}{ RAMPAS } \\
\hline \multicolumn{5}{|l|}{ 1. Dotadas de corrimão e rodapé (NR18)? } \\
\hline \multicolumn{5}{|l|}{ 2. Sem risco de escorregamento (NR8)? } \\
\hline \multicolumn{5}{|l|}{$\begin{array}{l}\text { 3. Oferecem resistência suficiente para suportar as cargas móveis e } \\
\text { fixas para as quais a edificação se destina (NR8)? }\end{array}$} \\
\hline \multicolumn{5}{|l|}{ INSTALAÇŌES ELÉTRICAS } \\
\hline 1. Todo o maquinário ou equipamento está aterrado (NR10)? & & & & \\
\hline 2. Cada máquina tem um interruptor de emergência? & & & & \\
\hline 3. Os interruptores de emergência estão visíveis? & & & & \\
\hline 4. Os funcionários utilizam somente tomadas independentes? & & & & \\
\hline 5. A chave geral da máquina está ao alcance do operador? & & & & \\
\hline 6. Os painéis elétricos estão desobstruídos e demarcados? & & & & \\
\hline 7. As tomadas, caixas e painéis elétricos possuem indicação de & & & & \\
\hline 8. Em caso de incêndio, pode-se desligar facilmente a chave geral? & & & & \\
\hline ORGANIZAÇÃO E LIMPEZA GERAL & & & & \\
\hline 1. Os locais de trabalho estão em ordem e limpos? & & & & \\
\hline 2. As áreas de circulação estão desobstruídas? & & & & \\
\hline 3. A limpeza é feita regularmente? & & & & \\
\hline 4. Há recipientes para coleta seletiva? & & & & \\
\hline ORGANIZAÇÃO DO TRABALHO & & & & \\
\hline 1. Sem excesso de horas-extras (mais de 10 horas por semana)? & & & & \\
\hline 2. Sem jornadas de trabalho prolongadas? & & & & \\
\hline 3. Sem sobrecarga individual devido à redução de funcionários? & & & & \\
\hline 4. Sem imposição de ritmos de trabalho excessivos? & & & & \\
\hline 5. Há esquema de substituição de funcionário faltante? & & & & \\
\hline
\end{tabular}

Legenda: S - Sim N - Não P - Parcialmente NA - Não se Aplica 


\begin{tabular}{|c|c|c|c|c|}
\hline \multirow{2}{*}{$\begin{array}{c}\text { LISTA DE VERIFICAÇÃO } \\
\text { INSPEÇÃO DE SEGURANÇA DO TRABALHO EM UNIDADES DE } \\
\text { BENEFICIAMENTO DE TOMATE } \\
\text { ASSUNTOS }\end{array}$} & \multicolumn{4}{|c|}{$\begin{array}{l}\text { Folha: } \\
\text { 2/5 }\end{array}$} \\
\hline & S & $\mathbf{N}$ & $\mathbf{P}$ & NA \\
\hline \multicolumn{5}{|l|}{ CONDIÇÕES AMBIENTAIS } \\
\hline \\
\hline \multicolumn{5}{|l|}{$\begin{array}{l}\text { 2. Os ruídos não interferem com a comunicação, a segurança ou a } \\
\text { eficiência do trabalho? }\end{array}$} \\
\hline \multicolumn{5}{|l|}{$\begin{array}{l}\text { 3. São realizadas manutenções periódicas nas máquinas a fim de } \\
\text { reduzir os níveis de ruído? }\end{array}$} \\
\hline \multicolumn{5}{|l|}{$\begin{array}{l}\text { 4. Na alimentação da esteira, no descarte, no armazenamento, no } \\
\text { carregamento e no descarregamento, a iluminância sobre a tarefa } \\
\text { mantida entre } 200 \text { e } 300 \text { lux? }\end{array}$} \\
\hline \multicolumn{5}{|l|}{$\begin{array}{l}\text { 5. Nas mesas de seleção, nas bicas e na pesagem, a iluminância } \\
\text { sobre a tarefa é mantida entre } 1000 \text { e } 1500 \text { lux? }\end{array}$} \\
\hline \multicolumn{5}{|l|}{ 6. A luz natural é usada também para a iluminação ambiental? } \\
\hline \multirow{2}{*}{\multicolumn{5}{|c|}{$\begin{array}{l}\text { 7. São realizadas periodicamente trocas de lâmpadas e limpeza das } \\
8 \text {. As reflexões e sombras são evitadas? }\end{array}$}} \\
\hline & \multicolumn{4}{|c|}{ 8. As reflexões e sombras são evitadas? } \\
\hline \multicolumn{5}{|l|}{$\begin{array}{l}\text { 9. Quando a temperaturas está elevada é empregado o esquema de } \\
\text { pausas previsto pela NR } 15 \text { ? }\end{array}$} \\
\hline \multicolumn{5}{|l|}{ EMPILHADEIRAS (NR 11) } \\
\hline \multicolumn{5}{|l|}{ 1. Os operadores estão habilitados a operá-las? } \\
\hline \multicolumn{5}{|l|}{$\begin{array}{l}\text { 2. Está indicada em lugar visível a carga máxima de trabalho } \\
\text { permitida na empilhadeira? }\end{array}$} \\
\hline \multirow{2}{*}{\multicolumn{5}{|c|}{$\begin{array}{l}\text { 3. As empilhadeiras possuem dispositivos de advertência sonora } \\
\text { PALETEIRAS }\end{array}$}} \\
\hline & & & & \\
\hline \multicolumn{5}{|l|}{ 1. Os garfos estão bem centralizados sob o palete? } \\
\hline \multicolumn{5}{|l|}{ 2. Não está sendo operada com cargas em rampas? } \\
\hline \multicolumn{5}{|l|}{ 3. Não é utilizada para transportar pessoas? } \\
\hline \multicolumn{5}{|l|}{ 4. Está sendo operada com prudência? } \\
\hline \multicolumn{5}{|l|}{ CONDIÇÕES DAS CAIXAS } \\
\hline \multicolumn{5}{|l|}{ 1. Livres de grampos, pregos expostos e de farpas de madeira? } \\
\hline \multirow{2}{*}{\multicolumn{5}{|c|}{$\begin{array}{l}\text { 2. Boa pega? } \\
\text { ARMAZENAMENTO DE CAIXAS (NR } 11\end{array}$}} \\
\hline & & & & \\
\hline \multicolumn{5}{|l|}{$\begin{array}{l}\text { 1. O material estocado não obstrui portas, equipamentos contra } \\
\text { incêndio, painéis elétricos e saídas de emergência? }\end{array}$} \\
\hline \multicolumn{5}{|l|}{$\begin{array}{l}\text { 2. O material estocado está afastado das estruturas laterais do } \\
\text { prédio a uma distância de pelo menos } 50 \mathrm{~cm} \text { ? }\end{array}$} \\
\hline EQUIPAMENTOS DE COMBATE A INCÉNDIO & & & & \\
\hline 1. Existem extintores e hidrantes no local? & & & & \\
\hline 2. Há funcionários habilitados para o uso dos extintores e hidrantes? & & & & \\
\hline 3. Os extintores são adequados às possíveis classes de fogo? & & & & \\
\hline 4. Os extintores estão carregados e de acordo com os prazos de & & & & \\
\hline 5. Os extintores e hidrantes estão desobstruídos? & & & & \\
\hline 6. As áreas dos extintores estão demarcadas? & & & & \\
\hline 7. Existem alarmes de incêndio? & & & & \\
\hline ESCADAS PORTÁTEIS & & & & \\
\hline 1. Com sabatas de borracha? & & & & \\
\hline 2. Degraus e montantes estão em bom estado de uso? & & & & \\
\hline SINALIZAÇÃO & & & & \\
\hline 1. Os locais de passagens de pedestre estão demarcados? & & & & \\
\hline 2. Os extintores e hidrantes estão sinalizados? & & & & \\
\hline 3. As tomadas, caixas e painéis elétricos possuem indicação de & & & & \\
\hline 4. Os painéis elétricos estão demarcados? & & & & \\
\hline 5. Existem placas informando sobre o tráfego de empilhadeiras? & & & & \\
\hline
\end{tabular}

\section{Legenda: S - Sim N - Não P - Parcialmente NA - Não se Aplica}




\begin{tabular}{|c|c|c|c|c|}
\hline \multirow{2}{*}{$\begin{array}{c}\text { LISTA DE VERIFICAÇÃO } \\
\text { INSPEÇÃO DE SEGURANÇA DO TRABALHO EM UNIDADES DE } \\
\text { BENEFICIAMENTO DE TOMATE } \\
\text { ASSUNTOS }\end{array}$} & \multicolumn{4}{|c|}{$\begin{array}{l}\text { Folha: } \\
\text { 3/5 }\end{array}$} \\
\hline & $S$ & $\mathbf{N}$ & P & NA \\
\hline \multicolumn{5}{|l|}{ MÁQUINAS E EQUIPAMENTOS (NR 12) } \\
\hline \multicolumn{5}{|l|}{$\begin{array}{l}\text { 1. As áreas de circulação e os espaços em torno das máquinas } \\
\text { foram dimensionados de forma que o material, os trabalhadores e os } \\
\text { transportadores mecanizados possam se movimentar com } \\
\text { segurança? }\end{array}$} \\
\hline \multicolumn{5}{|l|}{ 2. A distância mínima entre as máquinas é de 60 a $80 \mathrm{~cm}$ ? } \\
\hline \multicolumn{5}{|l|}{$\begin{array}{l}\text { 3. As máquinas e equipamentos estão com as correias, polias, } \\
\text { hélices e engrenagens enclausuradas dentro de sua estrutura ou } \\
\text { devidamente isoladas por anteparos adequados? }\end{array}$} \\
\hline \multicolumn{5}{|l|}{$\begin{array}{l}\text { 4. As correias, polias, hélices e engrenagens das máquinas e } \\
\text { equipamentos estão em perfeitas condições? }\end{array}$} \\
\hline \multicolumn{5}{|l|}{ 5. As máquinas são lubrificadas freqüentemente? } \\
\hline \multicolumn{5}{|l|}{$\begin{array}{l}\text { 6. Os botões de parada de emergência das máquinas são visíveis e } \\
\text { estão situados próximos ao operador? }\end{array}$} \\
\hline \multicolumn{5}{|l|}{ 7. Existe um programa de manutenção preventiva? } \\
\hline \multirow{2}{*}{\multicolumn{5}{|c|}{$\begin{array}{l}\text { 8. Os funcionários foram treinados? } \\
\text { EQUIPAMENTO DE PROTEÇÃO INDIVIDUAL - E.P.I. (NR 6) }\end{array}$}} \\
\hline & & & & \\
\hline \multicolumn{5}{|l|}{ 1. Os funcionários recebem E.P.I.? } \\
\hline \multicolumn{5}{|l|}{ 2. Os funcionários são obrigados a utilizar os E.P.I.? } \\
\hline \multicolumn{5}{|l|}{ 3. Os E.P.I. possuem C.A. (Certificado de Aprovação)? } \\
\hline \multicolumn{5}{|l|}{ 4. Os funcionários utilizam os E.P.I. corretamente? } \\
\hline \multicolumn{5}{|l|}{ 5. Os funcionários recebem E.P.I. adequados ao risco de cada } \\
\hline \multicolumn{5}{|l|}{$\begin{array}{l}\text { 6. Os funcionários foram orientados e treinados, no que diz respeito } \\
\text { ao uso adequado, guarda e conservação dos E.P.I.? }\end{array}$} \\
\hline \multicolumn{5}{|l|}{ 7. Os E.P.I. são substituídos imediatamente quando danificados ou } \\
\hline \multicolumn{5}{|l|}{ 8. Os E.P.I. são higienizados? } \\
\hline \multicolumn{5}{|l|}{$\begin{array}{l}\text { 9. Os funcionários que trabalham no tombamento de caixas utilizam } \\
\text { luvas de raspa ou vaqueta e calçado de segurança com biqueira de } \\
\text { aço? }\end{array}$} \\
\hline \multicolumn{5}{|l|}{$\begin{array}{l}\text { 10. Os funcionários que trabalham na mesa de seleção, utilizam } \\
\text { luvas de látex, máscara respiratória descartável e calçado de } \\
\text { segurança com biqueira de aço? }\end{array}$} \\
\hline \multicolumn{5}{|l|}{$\begin{array}{l}\text { 11. Os funcionários que trabalham na pesagem das caixas utilizam } \\
\text { luvas de raspa ou vaqueta e calçado de segurança com biqueira de } \\
\text { aço? }\end{array}$} \\
\hline \multicolumn{5}{|l|}{$\begin{array}{l}\text { 12. Os funcionários que trabalham no armazenamento utilizam luvas } \\
\text { de raspa ou vaqueta e calçado de segurança com biqueira de aço? }\end{array}$} \\
\hline \multicolumn{5}{|l|}{ 13. Os funcionários que trabalham no carregamento $\mathrm{e}$ no } \\
\hline \multicolumn{5}{|l|}{ 14. Os funcionários que trabalham na montagem de caixas de } \\
\hline \multicolumn{5}{|l|}{$\begin{array}{l}\text { 15. Os empilhadeiristas utilizam luvas de raspa ou vaqueta e } \\
\text { calçados de segurança com biqueira de aço, durante o manuseio de } \\
\text { caixas? }\end{array}$} \\
\hline $\begin{array}{l}\text { 16. Todos os funcionários utilizam protetores auriculares se o ruído } \\
\text { for superior a } 85 \mathrm{~dB}(\mathrm{~A}) \text { ? }\end{array}$ & & & & \\
\hline
\end{tabular}

Legenda: S - Sim N - Não P - Parcialmente NA - Não se Aplica 


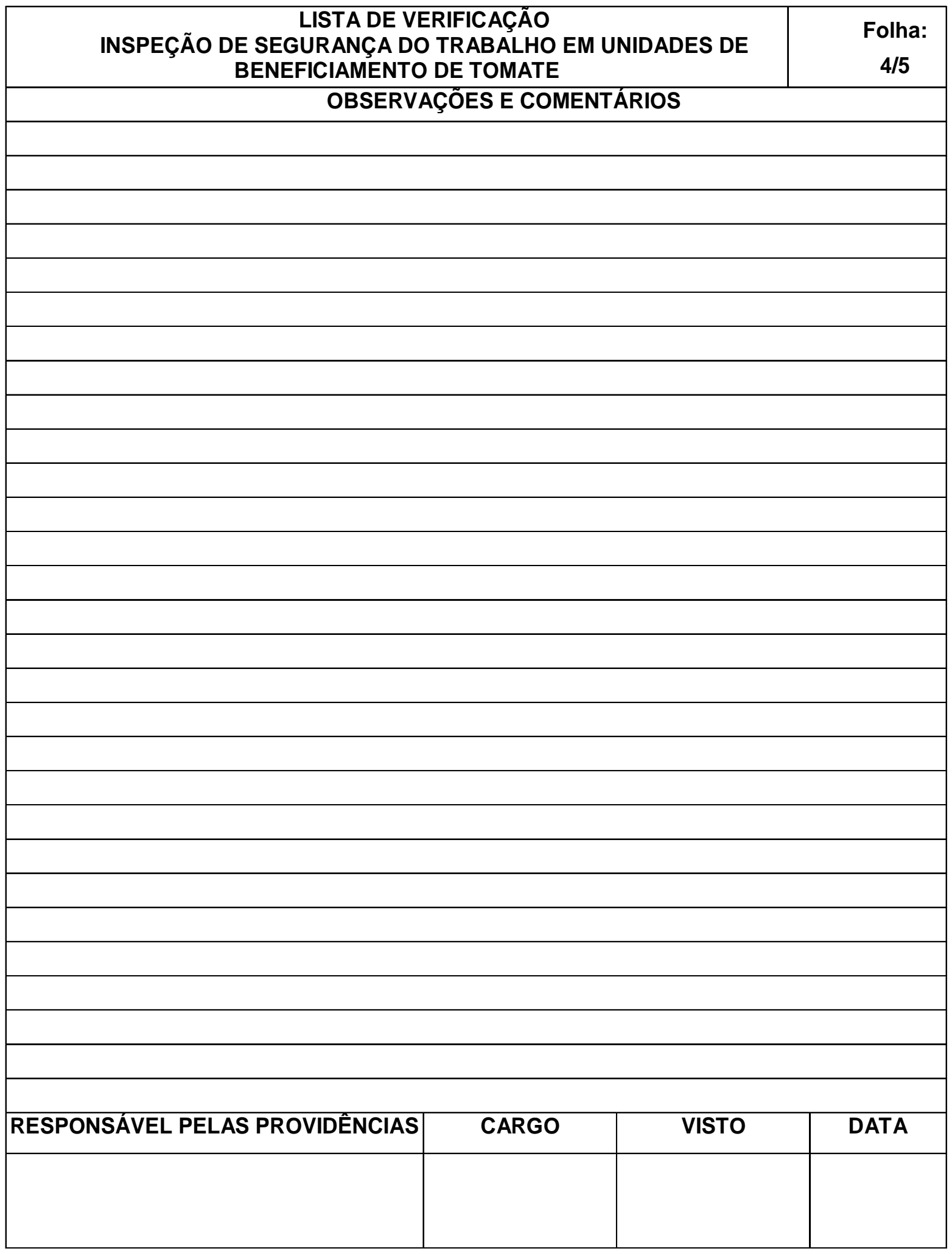

